\title{
Factors for Predicting Noninvasive Ventilation Failure in Elderly Patients with Respiratory Failure
}

\author{
Min Jeong Park ${ }^{1}{ }^{(}$, Jae Hwa Cho ${ }^{2}\left(\mathbb{D}\right.$, Youjin Chang ${ }^{3}$, Jae Young Moon ${ }^{4}$, Sunghoon Park ${ }^{5}$, \\ Tai Sun Park ${ }^{6}$ and Young Seok Lee ${ }^{7, *(D)}$ \\ 1 Department of Internal Medicine, Korea Medical Center, Guro Hospital, Seoul 08308, Korea; \\ minjeong87@gmail.com \\ 2 Department of Internal Medicine, Gangnam Severance Hospital, Yonsei University College of Medicine, \\ Seoul 06273, Korea; jhchomd@gmail.com \\ 3 Department of Pulmonary and Critical Care Medicine, Inje University Sanggye Paik Hospital, Seoul 01757, \\ Korea; yjchang0110@gmail.com \\ 4 Division of Pulmonology and Critical Care Medicine, Department of Internal Medicine, Chungnam National \\ University Hospital, Chungnam National University College of Medicine, Daejeon 35015, Korea; \\ diffable@hanmail.net \\ 5 Department of Pulmonary, Allergy and Critical Care Medicine, Hallym University Sacred Heart Hospital, \\ Anyang 14068, Korea; f2000tj@hallym.or.kr \\ 6 Department of Internal Medicine, Hanyang University College of Medicine, Seoul 04763, Korea; \\ integrin@hanmail.net \\ 7 Division of Respiratory and Critical Care Medicine, Korea Medical Center, Guro Hospital, 148, Gurodong-ro, \\ Guro-gu, Seoul 08308, Korea \\ * Correspondence: avonlea76@hanmail.net; Tel.: +82-2-2626-3256; Fax: +82-2-2626-1166
}

Received: 18 April 2020; Accepted: 29 June 2020; Published: 4 July 2020

\begin{abstract}
Noninvasive ventilation (NIV) is useful when managing critically ill patients. However, it is not easy to apply to elderly patients, particularly those with pneumonia, due to the possibility of NIV failure and the increased mortality caused by delayed intubation. In this prospective observational study, we explored whether NIV was appropriate for elderly patients with pneumonia, defined factors that independently predicted NIV failure, and built an optimal model for prediction of such failure. We evaluated 78 patients with a median age of 77 years. A low $\mathrm{PaCO}_{2}$ level, a high heart rate, and the presence of pneumonia were statistically significant independent predictors of NIV failure. The predictive power for NIV failure of Model III (pneumonia, $\mathrm{PaCO}_{2}$ level, and heart rate) was better than that of Model I (pneumonia alone). Considering the improvement in parameters, patients with successful NIV exhibited significantly improved heart rates, arterial $\mathrm{pH}$ and $\mathrm{PaCO}_{2}$ levels, and patients with NIV failure exhibited a significantly improved $\mathrm{PaCO}_{2}$ level only. In conclusion, NIV is reasonable to apply to elderly patients with pneumonia, but should be done with caution. For the early identification of NIV failure, the heart rate and arterial blood gas parameters should be monitored within $2 \mathrm{~h}$ after NIV commencement.
\end{abstract}

Keywords: noninvasive ventilation; respiratory failure; aged; intubation; critical illness

\section{Introduction}

Noninvasive ventilation (NIV) refers to ventilatory support delivered via a nasal, full- face, or helmet mask, without bypassing the upper airway, which is different from tracheal intubation or tracheostomy [1-4]. NIV is attractive when treating acute respiratory failure (RF), as it avoids complications, such as ventilator-associated pneumonia associated with invasive mechanical ventilation $[5,6]$. Although a high-flow nasal cannula (HFNC) may substitute for NIV when treating 
critically ill patients with acute hypoxic RF, it does not supply any inspiratory pressure, unlike NIV; therefore, NIV is preferred for patients with acute hypercapnic RF [7-11].

The proportion of elderly patients in intensive care units (ICUs) is rapidly growing, because global populations are aging [12]. If elderly patients require mechanical ventilation, weaning may be more prolonged than for younger patients, because of respiratory muscle weakness, comorbidities, and altered mental status [13-15]. Prolonged weaning is associated with several complications that increase in-hospital mortality [16-18]. Thus, many clinicians prefer to use a noninvasive approach, such as NIV, in elderly patients with acute RF to avoid intubations. However, in elderly patients, particularly those with pneumonia, there is concern regarding the possibility of NIV failure and the increased mortality caused by delayed intubation $[19,20]$. Thus, in elderly patients with pneumonia, NIV may be delayed, because its utility in this setting remains controversial, and excessive secretion (e.g., due to pneumonia) is a contraindication for the procedure. We hypothesized that, if we could define the factors that predict NIV failure so that it can encourage early intubation, rather than the maintenance of NIV, NIV could be safely applied to elderly patients with acute RF due to pneumonia.

The aim of this study was to investigate whether NIV was appropriate for elderly patients with pneumonia, to define factors that independently predicted NIV failure, and to make an optimal model for prediction of NIV failure.

\section{Materials and Methods}

\subsection{Study Overview}

This was a prospective observational study conducted at 21 university-affiliated hospitals of South Korea from June 2017 to February 2018. Among ICU patients prescribed NIV in accordance with international guidelines, we selected a subset by applying inclusion and exclusion criteria. The NIV machines, interfaces, and circuits were selected by respiratory intensivists from among the equipment available; the intensivists also chose initial NIV settings and durations by reference to patient conditions and the international guidelines. Patients who deteriorated after NIV underwent tracheal intubation at the discretion of respiratory intensivists. The study was approved by the Institutional Review Boards (IRBs) of all participating hospitals and the Korea Medical Center IRB (approval no.: 2017GR1298). Written informed consent was obtained from all enrolled patients or their legal surrogates.

\subsection{Patients}

The inclusion criteria were age $\geq 65$ years and NIV prescribed at admission or during the hospital stay because of acute hypoxic/hypercapnic RF or acute on chronic RF. The exclusion criteria were age $<65$ years; a lack of written informed consent; NIV use despite contraindications, such as myocardial infarction or post cardiac arrest; NIV use because of acute postoperative RF; NIV weaning; and NIV palliative therapy.

\subsection{Definitions}

Acute RF was divided into acute hypoxic and acute hypercapnic RF. Acute hypoxic RF was defined by a partial pressure of arterial oxygen $\left(\mathrm{PaO}_{2}\right) /$ percentage of inspired oxygen $\left(\mathrm{FiO}_{2}\right) \leq 300$ and a normal or low partial pressure of arterial carbon dioxide $\left(\mathrm{PaCO}_{2}\right)$. Acute hypercapnic $\mathrm{RF}$ was defined as a $\mathrm{PaCO}_{2}>50 \mathrm{mmHg}[21,22]$. Acute on chronic RF was defined as acute deterioration of RF caused by various factors in patients on home ventilators because of chronic disease. Age and body mass index (BMI; weight divided by the height squared) were treated as continuous variables. Pneumonia was diagnosed based on typical symptoms (e.g., fever, cough), elevated levels of inflammatory markers, and pneumonic consolidation evident in chest $X$-rays. Cardiovascular disease was defined as a prior diagnosis of ischemic heart disease, heart failure, or hypertension. Cerebrovascular disease was defined as a previous diagnosis of cerebral infarction or hemorrhage. Other comorbidities were defined using the traditional indicators. ICU mortality was death between ICU admission and discharge. 
NIV success was defined as successful weaning and then discontinuation. For chronic NIV users, NIV success was defined as transfer to a general ward because of stable gas parameters (e.g., $\mathrm{PaO}_{2} / \mathrm{FiO}_{2}>$ 300 or $\mathrm{PaCO}_{2}<50 \mathrm{mmHg}$ ) when on NIV and resolution of any acute exacerbation. NIV failure was defined as a transition to mechanical ventilation (via tracheal intubation or tracheostomy), a "hopeless" discharge on NIV, or death while on NIV.

\subsection{Statistical Analysis}

Descriptive statistics are presented as medians (the 25th to 75th percentiles) or as numbers (percentages). The Fisher's exact test was used to analyze categorical data, and the Mann-Whitney $U$-test was used to compare continuous data. The Wilcoxon signed-rank test was employed to determine the effects of NIV on physiological and laboratory parameters. Logistic regression analyses were used to identify factors independently predicting NIV failure. Independent variables and those with $p$-values $<0.1$ in univariate analyses were included in multivariate analyses. The data are presented as adjusted odds ratios (ORs) with $95 \%$ confidence intervals (CIs). We sought a model that optimally predicted NIV failure. The discriminatory power of each tested model was assessed using the Harrell C-index and the area under the curve (AUC); the models were compared using a bootstrap method. A two-tailed $p$-value $<0.05$ was taken to indicate significance. All statistical analyses were performed using SAS ver. 9.4 software (SAS Institute, Cary, NC, USA).

\section{Results}

\subsection{Clinical Characteristics}

During the study period, 200 patients received NIV therapy. Of these, 122 were excluded (refusal to consent, $n=36$; age $<65$ years, $n=37$; NIV weaning, $n=40$; postoperative NIV, $n=3$; NIV after myocardial infarction, $n=1$; NIV after cardiac arrest, $n=3$; and palliative NIV, $n=2$ ); thus, 78 patients were included, of whom 46 patients experienced NIV success and 32 patients experienced NIV failure (Figure 1).

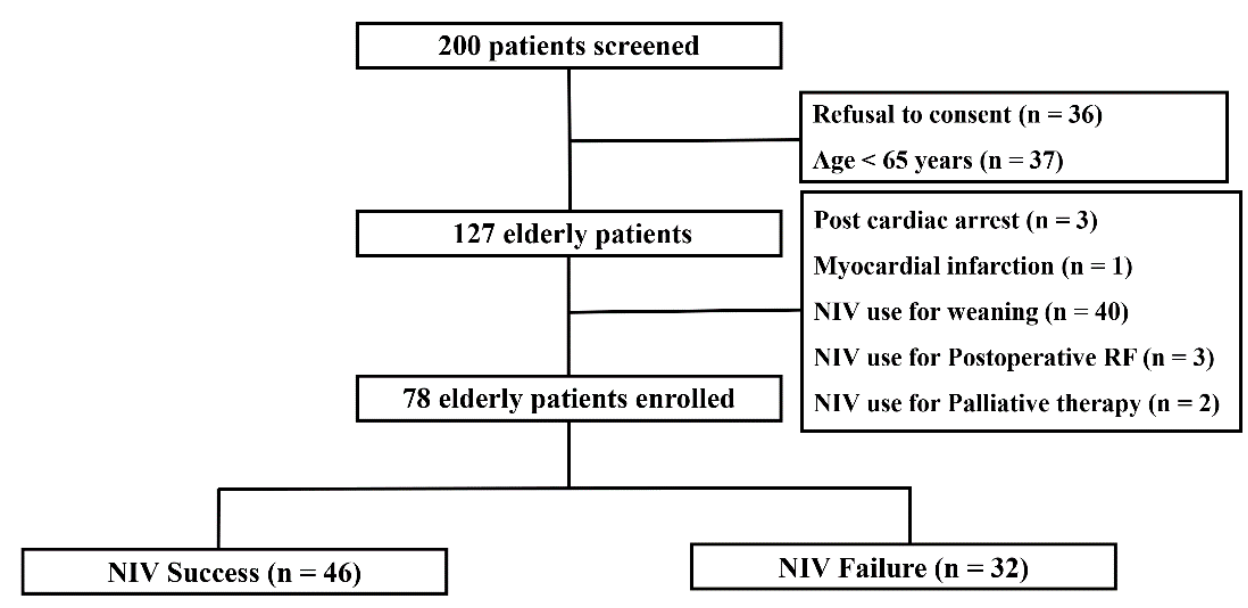

Figure 1. Flow chart of enrolled patients. NIV, noninvasive ventilation; RF, respiratory failure.

The clinical characteristics are listed in Table 1. The median age was 77 years and $43(55.1 \%)$ were male. The BMI value and sequential organ failure assessment (SOFA) score at NIV commencement were 20 and 4, respectively. Most patients $(76.9 \%)$ had been diagnosed with cardiovascular disease; one-third had been diagnosed with diabetes mellitus and chronic kidney disease. In all, 32 patients $(41 \%)$ had chronic obstructive pulmonary disease (COPD) and 20 (25.6\%) had no underlying lung disease. Patients who experienced NIV success versus failure did not differ demographically. The median NIV duration and ICU stay were 3 and 8 days. Patients for whom NIV was successful exhibited 
longer-duration NIV use and a shorter ICU stay (because they did not require intubation) than patients for whom NIV failed. Seventeen patients $(21.8 \%)$ died during ICU admission.

Table 1. Clinical characteristics of patients in this study.

\begin{tabular}{lcccc}
\hline \multicolumn{1}{c}{ Variables } & Total & \multicolumn{2}{c}{ Noninvasive Ventilation } & $p$-Value \\
\hline Age, years * & $n=78$ & Success $(n=46)$ & Failure $(n=32)$ & \\
Male & $77(72-82)$ & $78(73-82)$ & $76(70-82)$ & 0.542 \\
Body mass index, kg/m ${ }^{*}$ & $43(55.1)$ & $27(58.7)$ & $16(50)$ & 0.494 \\
SOFA score at the start of NIV * & $20(17-24)$ & $20(17-24)$ & $21(17-25)$ & 0.699 \\
Comorbidity & $4(2-5)$ & $3(2-5)$ & $4(2-6)$ & 0.216 \\
Cardiovascular disease & & & & \\
Diabetes mellitus & $60(76.9)$ & $26(56.5)$ & $17(53.1)$ & 0.820 \\
Chronic kidney disease & $21(26.9)$ & $11(23.9)$ & $10(31.3)$ & 0.605 \\
Liver cirrhosis & $14(17.9)$ & $8(17.4)$ & $6(18.8)$ & 1.000 \\
Cerebrovascular disease & $3(3.8)$ & $1(2.2)$ & $2(6.3)$ & 0.565 \\
Cancer & $9(11.5)$ & $5(10.9)$ & $4(12.5)$ & 1.000 \\
Immunosuppression & $7(9)$ & $3(6.5)$ & $4(12.5)$ & 0.436 \\
Underlying lung diseases & $6(7.7)$ & $1(2.2)$ & $5(15.6)$ & 0.040 \\
No underlying lung disease & $20(25.6)$ & $9(19.6)$ & $11(34.4)$ & 0.189 \\
COPD & $32(41)$ & $21(45.7)$ & $11(34.4)$ & 0.357 \\
Bronchial asthma & $2(2.6)$ & $1(2.2)$ & $1(3.1)$ & 1.000 \\
Interstitial lung disease & $5(6.4)$ & $2(4.3)$ & $3(9.4)$ & 0.396 \\
Bronchiectasis & $3(3.8)$ & $3(6.5)$ & $0(0)$ & 0.265 \\
TB destroyed lung disease & $8(10.3)$ & $4(8.7)$ & $4(12.5)$ & 0.710 \\
Neuromuscular disease & $1(1.3)$ & $0(0)$ & $1(3.1)$ & 0.410 \\
Obesity disease & $4(5.1)$ & $4(8.7)$ & $0(0)$ & 0.140 \\
Scoliosis & $1(1.3)$ & $1(2.2)$ & $0(0)$ & 1.000 \\
Others chest wall disease & $2(2.6)$ & $1(2.2)$ & $1(3.1)$ & 1.000 \\
Total duration of NIV use, days * & $3(2-8)$ & $4(2-7)$ & $2(1-5)$ & 0.042 \\
Duration of ICU stay, days * & $8(5-20)$ & $7(4-11)$ & $21(7-40)$ & $<0.001$ \\
ICU mortality & $17(21.8)$ & $0(0)$ & $17(53.1)$ & $<0.001$ \\
\hline
\end{tabular}

Abbreviations: SOFA, sequential organ failure assessment; NIV, non-invasive ventilation; COPD, chronic obstructive pulmonary disease; TB, tuberculosis; ICU, intensive care unit. * Data are presented as median (25th percentile-75th percentile). Other variables are presented as number (percent).

\subsection{Comparison of Treatment of Patients for Whom NIV Succeeded and Failed}

The NIV treatments of the two groups are compared in Table 2. Most NIV patients had hypercapnic RF and more patients with hypercapnic RF experienced NIV success than failure. The median $\mathrm{PaO}_{2} / \mathrm{FiO}_{2}$ ratio and $\mathrm{PaCO}_{2}$ values of these patients were 211 and $65 \mathrm{mmHg}$, respectively. Considering heart and respiratory rates, the $\mathrm{PaO}_{2} / \mathrm{FiO}$ ratio, and $\mathrm{PaCO}_{2}$, patients for whom NIV was successful had milder disease than those for whom NIV failed. Most patients were initially prescribed NIV in an ICU; patients prescribed NIV in general wards were transferred to ICUs. Most patients used oronasal masks. Typically, the initial NIV setting was pressure support mode; the initial IPAP and EPAP settings were 15 and $5 \mathrm{~cm} \mathrm{H}_{2} \mathrm{O}$. Eleven patients required sedatives during NIV; NIV was delivered for $15 \mathrm{~h} /$ day. Almost $15 \%$ of patients experienced skin erythema and large leakages, but the two groups did not differ significantly. 
Table 2. Comparison of treatment of patients for whom NIV succeeded and failed.

\begin{tabular}{|c|c|c|c|c|}
\hline \multirow[t]{2}{*}{ Variables } & \multirow{2}{*}{$\begin{array}{c}\text { Total } \\
n=78\end{array}$} & \multicolumn{2}{|c|}{ Noninvasive Ventilation } & \multirow[t]{2}{*}{$p$-Value } \\
\hline & & Success $(n=46)$ & Failure $(n=32)$ & \\
\hline \multicolumn{5}{|l|}{ Cause of the NIV application } \\
\hline Hypercapnic RF & $54(69.2)$ & $35(76.1)$ & $19(59.4)$ & 0.139 \\
\hline Hypoxic RF & $13(16.7)$ & $3(6.5)$ & $10(31.3)$ & 0.006 \\
\hline Acute on chronic RF & $11(14.1)$ & $8(17.4)$ & $3(9.4)$ & 0.510 \\
\hline \multicolumn{5}{|l|}{$\begin{array}{l}\text { Physiologic parameters on the } \\
\text { application of NIV * }\end{array}$} \\
\hline Systolic BP (mmHg) & $125(108-144)$ & $123(106-142)$ & $126(112-150)$ & 0.318 \\
\hline Heart rate (beats/min) & $98(83-110)$ & $92(82-106)$ & $107(85-117)$ & 0.051 \\
\hline Respiratory rate (breaths/min) & $24(20-29)$ & $24(20-28)$ & $27(23-32)$ & 0.030 \\
\hline Arterial pH & $7.34(7.28-7.39)$ & $7.34(7.29-7.38)$ & $7.34(7.27-7.43)$ & 0.830 \\
\hline $\mathrm{PaO}_{2} / \mathrm{FiO}_{2}$ ratio & $211(139-264)$ & $214(142-270)$ & $199(100-259)$ & 0.152 \\
\hline $\mathrm{PaCO}_{2}(\mathrm{mmHg})$ & $65(50-80)$ & $69(59-83)$ & $53(43-68)$ & 0.003 \\
\hline Location of initial NIV application & & & & 0.131 \\
\hline Intensive Care Unit & $70(89.7)$ & $39(84.8)$ & $31(96.9)$ & \\
\hline General ward & $8(10.3)$ & $7(15.2)$ & $1(3.1)$ & \\
\hline \multicolumn{5}{|l|}{ Interface type } \\
\hline Nasal type & $3(3.8)$ & $2(4.3)$ & $1(3.1)$ & 1.000 \\
\hline Oronasal type & $68(87.2)$ & $41(89.1)$ & $27(84.4)$ & 0.732 \\
\hline Total facial type & $1(1.3)$ & $0(0)$ & $1(3.1)$ & 0.410 \\
\hline Helmet type & $6(7.7)$ & $3(6.5)$ & $3(9.4)$ & 0.685 \\
\hline Initial mode & & & & 0.119 \\
\hline Assist control mode & $21(26.9)$ & $9(19.6)$ & $12(37.5)$ & \\
\hline Pressure support mode & $57(73.1)$ & $37(80.4)$ & $20(62.5)$ & \\
\hline \multicolumn{5}{|l|}{ Initial setting * } \\
\hline $\operatorname{IPAP}\left(\mathrm{cmH}_{2} \mathrm{O}\right)$ & $15(12-18)$ & $14(12-17)$ & $15(13-20)$ & 0.199 \\
\hline $\operatorname{EPAP}\left(\mathrm{cmH}_{2} \mathrm{O}\right)$ & $5(4-6)$ & $5(4-5)$ & $5(4-6)$ & 0.129 \\
\hline Tidal volume $(\mathrm{mL})$ & $400(309-514)$ & $390(303-505)$ & $410(334-569)$ & 0.308 \\
\hline Sedative use & $11(14.1)$ & $5(10.9)$ & $6(18.8)$ & 0.344 \\
\hline \multicolumn{5}{|l|}{ Complications during NIV } \\
\hline Skin erythema & $12(15.4)$ & $8(17.4)$ & $4(12.5)$ & 0.752 \\
\hline Abdominal distension & $4(6.4)$ & $3(6.5)$ & $2(6.3)$ & 1.000 \\
\hline Dry mouth & $3(3.8)$ & $2(4.3)$ & $1(3.1)$ & 1.000 \\
\hline Aspiration & $2(2.6)$ & $2(4.3)$ & $0(0)$ & 0.510 \\
\hline Claustrophobia & $1(1.3)$ & $1(2.2)$ & $0(0)$ & 1.000 \\
\hline Nasal congestion & $1(1.3)$ & $0(0)$ & $1(3.1)$ & 0.410 \\
\hline Large leaks & $11(14.1)$ & $5(10.9)$ & $6(18.8)$ & 0.344 \\
\hline Duration of NIV (hours/day) * & $15(7-22)$ & $16(10-21)$ & $12(3-24)$ & 0.449 \\
\hline
\end{tabular}

Abbreviations: NIV, non-invasive ventilation; RF, respiratory failure; $\mathrm{BP}$, blood pressure; $\mathrm{PaO}_{2}$, arterial partial pressure of oxygen; $\mathrm{FiO}_{2}$, fraction of inspired oxygen; $\mathrm{PaCO}_{2}$, arterial partial pressure of carbon dioxide; IPAP, inspiratory positive airway pressure; EPAP, expiratory positive airway pressure. * Data are presented as median (25th percentile-75th percentile). Other variables are presented as number (percent).

\subsection{Causes and Outcomes in Patients with NIV Failure}

The causes and outcomes of NIV failure are shown in Table 3. Among the 32 patients, 24 (75\%) experienced NIV failure, because of an aggravated clinical condition. Five patients complained of discomfort due to NIV commencement; NIV was discontinued in these patients. Most patients with NIV failure were intubated and received mechanical ventilation. Nine patients died during NIV. 
Table 3. Causes and Outcomes in patients with NIV failure $(n=32)$.

\begin{tabular}{lc}
\hline \multicolumn{1}{c}{ Variables } & Number (\%) \\
\hline Cause of NIV failure & \\
Aggravated clinical conditions & $24(75)$ \\
Agitation & $1(3.1)$ \\
Aspiration & $2(6.3)$ \\
Patients discomfort & $5(15.6)$ \\
Outcomes after NIV failure & $22(68.8)$ \\
Intubation \& Mechanical ventilation & $1(3.1)$ \\
Hopeless discharge with NIV & $9(28.1)$ \\
Death during NIV treatment &
\end{tabular}

Abbreviations: NIV, non-invasive ventilation.

\subsection{Factors Analyzed for Effects on NIV Success/Failure}

Patients with pneumonia at admission were significantly more likely to experience NIV failure, compared to those without pneumonia (Figure S1; $p=0.020$ ). We used logistic regression to identify factors associated with failure. Univariate analyses showed that the heart and respiratory rates, the $\mathrm{PaO}_{2} / \mathrm{FiO}_{2}$ ratio, $\mathrm{PaCO}_{2}$, use of the assist control mode, and pneumonia were significantly associated with NIV failure. Multivariate logistic regression (using backward elimination) revealed that a low $\mathrm{PaCO}_{2}(\mathrm{OR}, 0.95 ; 95 \% \mathrm{CI}, 0.910-0.982 ; p=0.004)$, a high heart rate (OR, 1.05; 95\% CI, 1.013-1.080; $p=0.006)$, and pneumonia (OR, 3.32; 95\% CI, 1.026-10.719; $p=0.045)$ were significant independent predictors of NIV failure (Table 4).

Table 4. Factors analyzed for effects on NIV success/failure.

\begin{tabular}{|c|c|c|c|}
\hline Variables & Odds Ratios & $95 \% \mathrm{CI}$ & $p$-Value \\
\hline \multicolumn{4}{|l|}{ Univariate Analysis } \\
\hline Age (years) & 0.99 & $0.929-1.055$ & 0.753 \\
\hline Male & 0.70 & $0.284-1.745$ & 0.448 \\
\hline Body mass index $\left(\mathrm{kg} / \mathrm{m}^{2}\right)$ & 0.99 & $0.912-1.072$ & 0.787 \\
\hline SOFA score at the start of NIV & 1.17 & $0.955-1.433$ & 0.130 \\
\hline Systolic blood pressure (mmHg) & 1.02 & 0.995-1.036 & 0.136 \\
\hline Heart rate (beats/min) after NIV & 1.04 & $1.009-1.066$ & 0.010 \\
\hline Respiratory rate (breaths/min) after NIV & 1.09 & $1.001-1.187$ & 0.047 \\
\hline $\mathrm{PaO}_{2} / \mathrm{FiO}_{2}$ ratio after NIV & 0.99 & $0.988-1.001$ & 0.074 \\
\hline $\mathrm{PaCO}_{2}(\mathrm{mmHg})$ after NIV & 0.95 & $0.916-0.980$ & 0.002 \\
\hline The number of comorbidities & 1.29 & $0.849-1.966$ & 0.232 \\
\hline Assist control mode & 2.47 & $0.888-6.849$ & 0.083 \\
\hline IPAP & 1.06 & $0.943-1.185$ & 0.344 \\
\hline EPAP & 1.23 & $0.904-1.667$ & 0.189 \\
\hline Sedative use & 1.89 & $0.524-6.837$ & 0.330 \\
\hline Large leak & 1.89 & $0.524-6.837$ & 0.330 \\
\hline NIV application time during a day & 0.97 & $0.920-1.031$ & 0.360 \\
\hline The presence of pneumonia & 3.69 & $1.314-10.389$ & 0.013 \\
\hline \multicolumn{4}{|l|}{ Multivariate Analysis } \\
\hline $\mathrm{PaCO}_{2}(\mathrm{mmHg})$ after NIV & 0.95 & $0.910-0.982$ & 0.004 \\
\hline Heart rate (beats/min) after NIV & 1.05 & $1.013-1.080$ & 0.006 \\
\hline The presence of pneumonia & 3.32 & $1.026-10.719$ & 0.045 \\
\hline
\end{tabular}

Abbreviations: $\mathrm{CI}$, confidence interval; SOFA, sequential organ failure assessment; NIV, non-invasive ventilation; $\mathrm{PaO}_{2}$, arterial partial pressure of oxygen; $\mathrm{FiO}_{2}$, fraction of inspired oxygen; $\mathrm{PaCO}_{2}$, arterial partial pressure of carbon dioxide; IPAP, inspiratory positive airway pressure; EPAP, expiratory positive airway pressure. Multivariate logistic regression analysis that used backward elimination was performed to predict noninvasive ventilation failure after adjusting for six variables (Heart rate (beats/min) after NIV, Respiratory rate (breaths/min) after NIV, $\mathrm{PaCO}_{2}$ $(\mathrm{mmHg})$ after NIV, $\mathrm{PaO}_{2} / \mathrm{FiO}_{2}$ ratio after NIV, Assist control mode and the presence of pneumonia). 


\subsection{Prognostic Utilities of Models Using Risk Factors for NIV Failure}

The Harrell C-index was used to compare different combinations of factors, and pneumonia status, in terms of NIV failure prediction. Model I included only pneumonia; Model II included pneumonia and heart rate; and Model III included pneumonia, $\mathrm{PaCO}_{2}$ level, and heart rate. Model I predicted NIV failure poorly (C-index AUC: $0.639 ; 95 \%$ CI: 0.534-0.744). Models II and III were slightly better (Model II: 0.744; Model III: 0.816). The differences in the AUCs of Models II and III (compared to that of Model I) were significant (Model II: $p=0.025$; Model III: $p=0.001$ ) (Table 5).

Table 5. Prognostic utilities of models using risk factors for noninvasive ventilation failure.

\begin{tabular}{ccccc}
\hline Models & C-Index & $\mathbf{9 5 \% ~ C I ~}$ & $p$-Value ${ }^{*}$ & $p$-Value ${ }^{\dagger}$ \\
\hline I & 0.639 & $0.534-0.744$ & Reference & \\
II & 0.744 & $0.630-0.859$ & 0.025 & Reference \\
III & 0.816 & $0.715-0.917$ & 0.001 & 0.052 \\
\hline
\end{tabular}

Model I included only the presence of pneumonia. Model II included the presence of pneumonia and Heart rate (beats/min) after NIV. Model III included the presence of pneumonia, $\mathrm{PaCO}_{2}(\mathrm{mmHg})$ after NIV, and heart rate (beats/min) after NIV. *, $p$-value for the difference in the AUCs compared to Model I, $\dagger, p$-value for comparison between Model II and Model III.

Therefore, not only pneumonia status, but also a vital sign (heart rate) and arterial blood gas status $\left(\mathrm{PaCO}_{2}\right)$ between $30 \mathrm{~min}$ and $2 \mathrm{~h}$ after NIV commencement, should be considered when predicting NIV failure.

\subsection{Changes in Physiological Parameters after NIV Commencement}

We collected arterial blood gas and vital sign data before NIV and between $30 \mathrm{~min}$ and $2 \mathrm{~h}$ after NIV commencement (Table 6). Patients for whom NIV was successful exhibited significantly improved heart rates and arterial $\mathrm{pH}$ and $\mathrm{PaCO}_{2}$ levels after NIV application. Patients for whom NIV failed evidenced a significantly improved $\mathrm{PaCO}_{2}$ level only. Therefore, patients without marked clinical improvement in both vital signs and arterial blood gas values 30-120 min after NIV commencement are at risk of NIV failure.

Table 6. Changes in physiological parameters after NIV commencement.

\begin{tabular}{|c|c|c|c|}
\hline Variables & \multicolumn{2}{|c|}{ NIV Application $(n=78)$} & \multirow[t]{2}{*}{$p$-Value } \\
\hline NIV Success $(n=46)$ & Before & After & \\
\hline Systolic blood pressure $(\mathrm{mmHg})$ & $123(106-142)$ & $117(104-129)$ & 0.056 \\
\hline Heart rate (beats/min) & $92(82-106)$ & $89(75-97)$ & 0.007 \\
\hline Respiratory rate (breaths/min) & $24(20-28)$ & $22(19-25)$ & 0.298 \\
\hline Arterial $\mathrm{pH}$ & $7.34(7.29-7.38)$ & $7.37(7.30-7.43)$ & $<0.001$ \\
\hline $\mathrm{PaO}_{2} / \mathrm{FiO}_{2}$ ratio & $214(142-270)$ & $233(179-271)$ & 0.298 \\
\hline $\mathrm{PaCO}_{2}(\mathrm{mmHg})$ & $69(59-83)$ & $63(51-75)$ & $<0.001$ \\
\hline \multicolumn{4}{|l|}{ NIV failure $(n=32)$} \\
\hline Systolic blood pressure $(\mathrm{mmHg})$ & $126(112-150)$ & $126(107-145)$ & 0.462 \\
\hline Heart rate (beats/min) & $107(85-117)$ & $97(89-114)$ & 0.296 \\
\hline Respiratory rate (breaths/min) & $27(23-32)$ & $24(21-28)$ & 0.159 \\
\hline Arterial $\mathrm{pH}$ & $7.34(7.27-7.43)$ & $7.36(7.31-7.43)$ & 0.082 \\
\hline $\mathrm{PaO}_{2} / \mathrm{FiO}_{2}$ ratio & $199(100-259)$ & $212(120-280)$ & 0.247 \\
\hline $\mathrm{PaCO}_{2}(\mathrm{mmHg})$ & $53(43-68)$ & $48(39-66)$ & 0.005 \\
\hline
\end{tabular}

Abbreviations: NIV, non-invasive ventilation; $\mathrm{PaO}_{2}$, arterial partial pressure of oxygen; $\mathrm{FiO}_{2}$, fraction of inspired oxygen; $\mathrm{PaCO}_{2}$, arterial partial pressure of carbon dioxide. Data are presented as median (25th percentile-75th percentile). The Wilcoxon signed-rank test was used to determine NIV effect for physiologic parameters and laboratory parameters after NIV application. 


\section{Discussion}

We explored whether NIV was appropriate for elderly patients with pneumonia, defined factors that independently predicted NIV failure, and built an optimal model for prediction of such failure. Pneumonia was associated with NIV failure, but the presence of pneumonia alone did not predict such failure well (C-index AUC: $0.639 ; 95 \%$ CI: 0.534-0.744). Therefore, NIV is not contraindicated by pneumonia alone. Improvement of heart rate and $\mathrm{PaCO}_{2}$ level measured within $2 \mathrm{~h}$ after NIV commencement should be considered when determining if NIV should be continued or if intubation is preferable.

Our study makes several important contributions to the literature. When elderly patients are admitted to ICUs, intensivists find it difficult to decide whether aggressive treatment is appropriate, because advanced age is associated with poorer outcomes after mechanical ventilation, and survival does not always ensure a satisfactory quality of life $[12-15,19,20,23,24]$. Some intensivists prefer to treat elderly patients as noninvasively as possible, often choosing NIV for those with acute RF. However, some may hesitate to use NIV in elderly patients with pneumonia on the basis of a vague concern that NIV failure is more common in elderly patients than in younger patients [25,26]. NIV failure is associated with poor mask-fitting, claustrophobia, excessive secretions, intolerance, agitation, and patient/ventilator asynchrony, most of which may be associated with poor respiratory muscle power [26,27]. A previous study also showed that weak respiratory muscle power was associated with NIV failure [27]. Generally, older patients have weaker respiratory muscles than younger patients. Thus, concerns that NIV failure is more common in elderly patients than in younger ones may be partially right. However, some elderly patients remain active and have powerful respiratory muscles. Therefore, NIV should not be avoided simply because of patient age. In our study, age subgrouping (65-74, 75-84, and $\geq 85$ years) did not affect the NIV failure rate (Figure S2; $p=0.535$ ).

Early identification of NIV failure is important; delayed identification increases mortality. In a previous study, the timing of NIV failure was categorized as follows: (1) immediate failure (within minutes to $<1 \mathrm{~h}$ ), (2) early failure (1-48 h), and (3) late failure (after $48 \mathrm{~h})$ [26]. The majority $(\sim 83 \%)$ of NIV failures occur between the immediate and early stages [26]. When evaluating possible NIV failure, it is necessary to consider the overall clinical condition, but we could hesitate to perform intubation if NIV failure is not definitive. We emphasize that early variation in vital signs and arterial blood gas data measured 30-120 min after NIV commencement should be used to predict NIV possible failure, triggering intubation, thus preventing mortality attributable to delayed intubation.

We found that heart rate and $\mathrm{PaCO}_{2}$ level independently predicted NIV failure. Although the $\mathrm{PaO}_{2} / \mathrm{FiO}_{2}$ ratio has been associated with NIV failure in patients with hypoxic respiratory failure, the arterial $\mathrm{pH}$ and $\mathrm{PaCO}_{2}$ values of patients with hypercapnic respiratory failure were more closely associated with NIV failure than the $\mathrm{PaO}_{2} / \mathrm{FiO}_{2}$ ratio [26]. In our study, $82.1 \%$ of patients were prescribed NIV, because of hypercapnic respiratory failure. Therefore, the $\mathrm{PaCO}_{2}$ value more meaningfully predicted NIV failure than the $\mathrm{PaO}_{2} / \mathrm{FiO}_{2}$ ratio.

In this study, a low $\mathrm{PaCO}_{2}$ level after NIV commencement was associated with NIV failure. A low $\mathrm{PaCO}_{2}$ level was associated with severe disease and agitation, because the increased tidal volume and tachypnea caused by labored breathing led to reduction of the $\mathrm{PaCO}_{2}$ level [28,29]. A PaCO 2 level after NIV commencement was related to a $\mathrm{PaCO}_{2}$ level before NIV commencement. Therefore, patients with a low $\mathrm{PaCO}_{2}$ level after NIV commencement initially had more severe disease, compared to patients with a high $\mathrm{PaCO}_{2}$ level after NIV commencement. Disease severity was associated with NIV failure, so NIV failure was more likely in patients with a low $\mathrm{PaCO}_{2}$ level than in patients with a high $\mathrm{PaCO}_{2}$ level. A more important finding related to the evaluation of NIV failure was the variation in $\mathrm{PaCO}_{2}$ level after NIV commencement. As shown in Table 6, variation in the $\mathrm{PaCO}_{2}$ level in the NIV failure group was associated with a less-improved arterial $\mathrm{pH}$ than that of the NIV success group. In other words, although the absolute median variation was similar in both groups, $\mathrm{PaCO}_{2}$ improvement was less clinically effective in the NIV failure group than in the NIV success group. This finding is probably because the number of patients with hypoxic respiratory failure was higher in NIV failure group than 
in NIV success group. However, a $\mathrm{PaCO}_{2}$ level reflects the clinical condition. Consequently, when predicting NIV failure, we should consider whether a $\mathrm{PaCO}_{2}$ level has improved properly to the point where $\mathrm{pH}$ reaches to the normal range. The results of a subgroup analysis of patients with only hypercapnic RF were similar to the findings in the present study (Table S1). The heart rate was also a significant independent predictor of NIV failure, because a high heart rate was associated with disease severity and agitation. Previous studies have reported that respiratory rate variation is associated with NIV failure [26]. However, in practice, respiratory rate measurement is less accurate than heart rate measurement, because the former is not automatic. Both the respiratory and heart rates are affected by clinical condition. Therefore, heart rate variation is preferable to respiratory rate variation when predicting NIV failure.

We also explored the utility of NIV in patients with pneumonia. This has been controversial; prior studies have reported conflicting results, probably because of differences in clinical characteristics (pneumonia severity, age, or comorbidities) [30-37]. In patients with pneumonia, the median $\mathrm{PaO}_{2} / \mathrm{FiO}_{2}$ ratio and the median SOFA score at NIV commencement were 155 and 5. All pneumonia patients of the present study suffered from sepsis. In addition, $55 \%$ of patients had underlying lung parenchymal disease (COPD, asthma, interstitial lung disease, or bronchiectasis). Therefore, pneumonia was severe. We found that the $C$ index of pneumonia alone was 0.639 ; thus, pneumonia was only weakly associated with NIV failure. Therefore, NIV is reasonable to apply in elderly patients with pneumonia, if we could carefully observe patients after NIV commencement.

Our study had certain limitations. First, the patient number was relatively small ( $n=78)$. However, the number was sufficient to reveal the factors associated with NIV failure in elderly patients with acute RF, because a post hoc power analysis revealed that the power of each variable was appropriate. Second, we did not include clinical data, such as chest X-ray or laboratory findings, when determining disease severity in patients with pneumonia. However, given the SOFA scores and $\mathrm{PaO}_{2} / \mathrm{FiO}_{2}$ ratios, most pneumonia patients suffered from sepsis. Third, we did not set detailed indications for weaning or intubation, relying rather on respiratory intensivist discretion. However, all intensivists had extensive experience with NIV, and most decisions were based on international guidelines.

\section{Conclusions}

NIV is reasonable to apply in elderly patients with pneumonia, if we could carefully observe patients after NIV commencement. For the early identification of NIV failure triggering immediate intubation, the heart rate and arterial blood gas parameters should be closely monitored between $30 \mathrm{~min}$ and $2 \mathrm{~h}$ after NIV commencement. Additional studies with larger patient cohorts are warranted to validate our findings.

Supplementary Materials: The following are available online at http://www.mdpi.com/2077-0383/9/7/2116/s1, Figure S1: Association between pneumonia at admission and NIV failure. Patients with pneumonia at admission were significantly more likely to experience NIV failure compared to those without pneumonia. Figure S2: The association between age subgroup and noninvasive ventilation failure. Age subgroup (65-74 years, 75-84 years, and 85 years over) was not associated with NIV failure $(p=0.535)$. Table S1: Changes in physiological parameters after NIV commencement in patients with hypercapnic respiratory failure alone.

Author Contributions: (1) Substantial contributions to the conception or design of the work: M.J.P., Y.S.L. (2) The acquisition, analysis, or interpretation of data for the work: M.J.P., J.H.C., Y.C., J.Y.M., S.P., T.S.P., Y.S.L. (3) Drafting the work of revising it critically for important intellectual content: M.J.P., J.H.C., Y.C., J.Y.M., S.P., T.S.P., Y.S.L. (4) Final approval of the version to be published: M.J.P., J.H.C., Y.C., J.Y.M., S.P., T.S.P., Y.S.L. All authors have read and agreed to the published version of the manuscript.

Funding: This study was supported by a 2017 grant from the Korea Academy of Tuberculosis and Respiratory Diseases.

Acknowledgments: We thank the following investigators for the participation in this study: Jin Woo Kim (The Catholic University of Korea, UiJeongbu St. Mary's Hospital), Jong Hoo Lee (Jeju National University Hospital), Tak Oak Kim (Chonnam National University Hospital), Yun Mi Sin (Chungbuk National University), Jik Hwan Ha (The Catholic University of Korea, Incheon St. Mary's Hospital), Eun Young Choi (Yeungnam University Hospital), Jae Joon Hwang (Kyung Hee University Hospital), Kwangha Lee (Pusan National University Hospital), Sei Won Kim (The Catholic University of Korea, St. Paul's Hospital), Hyung Koo Kang (Ilsan Paik 
Hospital), Yun Su Sim (Hallym University Kangnam Sacred Heart Hospital), and Seung Yong Park (Chonbuk National University Hospital).

Conflicts of Interest: The authors declare no conflict of interest.

\section{References}

1. Baudouin, S.; Blumenthal, S.; Cooper, B.; Davidson, C.; Davison, A.; Elliot, M.; Kinnear, W.; Paton, R.; Sawicka, E.; Turner, L. Noninvasive ventilation in acute respiratory failure. Thorax 2002, 57, $192-211$. [CrossRef]

2. Davidson, A.C.; Banham, S.; Elliott, M.; Kennedy, D.; Gelder, C.; Glossop, A.; Church, A.C.; Creagh-Brown, B.; Dodd, J.W.; Felton, T.; et al. BTS/ICS guideline for the ventilatory management of acute hypercapnic respiratory failure in adults. Thorax 2016, 71 (Suppl. 2), ii1-ii35. [CrossRef]

3. Rochwerg, B.; Brochard, L.; Elliott, M.W.; Hess, D.; Hill, N.S.; Nava, S.; Navalesi, P.M.O.T.S.C.; Antonelli, M.; Brozek, J.; Conti, G.; et al. Official ERS/ATS clinical practice guidelines: Noninvasive ventilation for acute respiratory failure. Eur. Respir. J. 2017, 50, 1602426. [CrossRef] [PubMed]

4. Bourke, S.C.; Piraino, T.; Pisani, L.; Brochard, L.; Elliott, M.W. Beyond the guidelines for non-invasive ventilation in acute respiratory failure: Implications for practice. Lancet Respir. Med. 2018, 6, $935-947$. [CrossRef]

5. Girou, E.; Schortgen, F.; Delclaux, C.; Brun-Buisson, C.; Blot, F.; Lefort, Y.; Lemaire, F.; Brochard, L. Association of noninvasive ventilation with nosocomial infections and survival in critically ill patients. JAMA 2000, 284, 2361-2367. [CrossRef] [PubMed]

6. Girou, E.; Brun-Buisson, C.; Taillé, S.; Lemaire, F.; Brochard, L. Secular trends in nosocomial infections and mortality associated with noninvasive ventilation in patients with exacerbation of COPD and pulmonary edema. JAMA 2003, 290, 2985-2991. [CrossRef] [PubMed]

7. Grieco, D.L.; Menga, L.S.; Raggi, V.; Bongiovanni, F.; Anzellotti, G.M.; Tanzarella, E.S.; Bocci, M.G.; Mercurio, G.; Dell'Anna, A.M.; Eleuteri, D.; et al. Physiological Comparison of High-Flow Nasal Cannula and Helmet Noninvasive Ventilation in Acute Hypoxemic Respiratory Failure. Am. J. Respir. Crit. Care Med. 2020, 201, 303-312. [CrossRef]

8. Ni, Y.N.; Luo, J.; Yu, H.; Liu, D.; Ni, Z.; Cheng, J.; Liang, B.M.; Liang, Z.A. Can High-flow Nasal Cannula Reduce the Rate of Endotracheal Intubation in Adult Patients With Acute Respiratory Failure Compared With Conventional Oxygen Therapy and Noninvasive Positive Pressure Ventilation?: A Systematic Review and Meta-analysis. Chest 2017, 151, 764-775. [CrossRef]

9. Xu, X.P.; Zhang, X.C.; Hu, S.L.; Xu, J.Y.; Xie, J.F.; Liu, S.Q.; Liu, L.; Huang, Y.Z.; Guo, F.M.; Yang, Y.; et al. Noninvasive Ventilation in Acute Hypoxemic Nonhypercapnic Respiratory Failure: A Systematic Review and Meta-Analysis. Crit. Care Med. 2017, 45, e727-e733. [CrossRef]

10. Frat, J.P.; Thille, A.W.; Mercat, A.; Girault, C.; Ragot, S.; Perbet, S.; Prat, G.; Boulain, T.; Morawiec, E.; Cottereau, A.; et al. High-flow oxygen through nasal cannula in acute hypoxemic respiratory failure. N. Engl. J. Med. 2015, 372, 2185-2196. [CrossRef]

11. Li, J.; Jing, G.; Scott, J.B. Year in Review 2019: High-Flow Nasal Cannula Oxygen Therapy for Adult Subjects. Respir Care 2020, 65, 545-557. [CrossRef] [PubMed]

12. Flaatten, H.; de Lange, D.W.; Artigas, A.; Bin, D.; Moreno, R.; Christensen, S.; Joynt, G.M.; Bagshaw, S.M.; Sprung, C.L.; Benoit, D.; et al. The status of intensive care medicine research and a future agenda for very old patients in the ICU. Intensive Care Med. 2017, 43, 1319-1328. [CrossRef] [PubMed]

13. Magalhães, P.A.F.; Camillo, C.A.; Langer, D.; Andrade, L.B.; Duarte, M.; Gosselink, R. Weaning failure and respiratory muscle function: What has been done and what can be improved? Respir. Med. 2018, 134, 54-61. [CrossRef] [PubMed]

14. Boles, J.M.; Bion, J.; Connors, A.; Herridge, M.; Marsh, B.; Melot, C.; Pearl, R.; Silverman, H.; Stanchina, M.; Vieillard-Baron, A.; et al. Weaning from mechanical ventilation. Eur. Respir. J. 2007, 29, 1033-1056. [CrossRef] [PubMed] 
15. Ely, E.W.; Wheeler, A.P.; Thompson, B.T.; Ancukiewicz, M.; Steinberg, K.P.; Bernard, G.R. Recovery rate and prognosis in older persons who develop acute lung injury and the acute respiratory distress syndrome. Ann. Intern. Med. 2002, 136, 25-36. [CrossRef] [PubMed]

16. Funk, G.C.; Anders, S.; Breyer, M.K.; Burghuber, O.C.; Edelmann, G.; Heindl, W.; Hinterholzer, G.; Kohansal, R.; Schuster, R.; Schwarzmaier-D'Assie, A.; et al. Incidence and outcome of weaning from mechanical ventilation according to new categories. Eur. Respir. J. 2010, 35, 88-94. [CrossRef]

17. Sellares, J.; Ferrer, M.; Cano, E.; Loureiro, H.; Valencia, M.; Torres, A. Predictors of prolonged weaning and survival during ventilator weaning in a respiratory ICU. Intensive Care Med. 2011, 37, 775-784. [CrossRef]

18. Béduneau, G.; Pham, T.; Schortgen, F.; Piquilloud, L.; Zogheib, E.; Jonas, M.; Grelon, F.; Runge, I.; Nicolas, T.; Grangé, S.; et al. Epidemiology of Weaning Outcome according to a New Definition. The WIND Study. Am. J. Respir. Crit. Care Med. 2017, 195, 772-783. [CrossRef]

19. Piroddi, I.M.G.; Barlascini, C.; Esquinas, A.; Braido, F.; Banfi, P.; Nicolini, A. Non-invasive mechanical ventilation in elderly patients: A narrative review. Geriatr. Gerontol. Int. 2017, 17, 689-696. [CrossRef]

20. Scala, R. Challenges on non-invasive ventilation to treat acute respiratory failure in the elderly. BMC Pulm. Med. 2016, 16, 150. [CrossRef]

21. Roussos, C.; Koutsoukou, A. Respiratory failure. Eur. Respir. J. Suppl. 2003, 47, 3-14. [CrossRef]

22. Pontoppidan, H.; Geffin, B.; Lowenstein, E. Acute respiratory failure in the adult. 1. N. Engl. J. Med. 1972, 287, 690-698. [CrossRef]

23. Guidet, B.; Leblanc, G.; Simon, T.; Woimant, M.; Quenot, J.P.; Ganansia, O.; Maignan, M.; Yordanov, Y.; Delerme, S.; Doumenc, B.; et al. Effect of Systematic Intensive Care Unit Triage on Long-term Mortality Among Critically Ill Elderly Patients in France: A Randomized Clinical Trial. JAMA 2017, 318, 1450-1459. [CrossRef]

24. Farfel, J.M.; Franca, S.A.; Sitta Mdo, C.; Filho, W.J.; Carvalho, C.R. Age, invasive ventilatory support and outcomes in elderly patients admitted to intensive care units. Age Ageing 2009, 38, 515-520. [CrossRef]

25. Antonelli, M.; Conti, G.; Moro, M.L.; Esquinas, A.; Gonzalez-Diaz, G.; Confalonieri, M.; Pelaia, P.; Principi, T.; Gregoretti, C.; Beltrame, F.; et al. Predictors of failure of noninvasive positive pressure ventilation in patients with acute hypoxemic respiratory failure: A multi-center study. Intensive Care Med. 2001, 27, 1718-1728. [CrossRef]

26. Ozyilmaz, E.; Ugurlu, A.O.; Nava, S. Timing of noninvasive ventilation failure: Causes, risk factors, and potential remedies. BMC Pulm. Med. 2014, 14, 19. [CrossRef]

27. Hong, Y.; Duan, J.; Bai, L.; Han, X.; Huang, S.; Guo, S. Noninvasive ventilation failure in pneumonia patients $\geq 65$ years old: The role of cough strength. J. Crit. Care 2018, 44, 149-153. [CrossRef]

28. Petersson, J.; Glenny, R.W. Gas exchange and ventilation-perfusion relationships in the lung. Eur. Respir. J. 2014, 44, 1023-1041. [CrossRef]

29. Sinha, P.; Fauvel, N.J.; Singh, S.; Soni, N. Ventilatory ratio: A simple bedside measure of ventilation. Br. J. Anaesth. 2009, 102, 692-697. [CrossRef]

30. He, H.; Sun, B.; Liang, L.; Li, Y.; Wang, H.; Wei, L.; Li, G.; Guo, S.; Duan, J.; Li, Y.; et al. A multicenter RCT of noninvasive ventilation in pneumonia-induced early mild acute respiratory distress syndrome. Crit. Care 2019, 23, 300. [CrossRef] [PubMed]

31. Carron, M.; Freo, U.; Zorzi, M.; Ori, C. Predictors of failure of noninvasive ventilation in patients with severe community-acquired pneumonia. J. Crit. Care 2010, 25, e549-e554. [CrossRef] [PubMed]

32. Confalonieri, M.; Potena, A.; Carbone, G.; Porta, R.D.; Tolley, E.A.; Umberto Meduri, G. Acute respiratory failure in patients with severe community-acquired pneumonia. A prospective randomized evaluation of noninvasive ventilation. Am. J. Respir. Crit. Care Med. 1999, 160, 1585-1591. [CrossRef] [PubMed]

33. Al-Rajhi, A.; Murad, A.; Li, P.Z.; Shahin, J. Outcomes and predictors of failure of non-invasive ventilation in patients with community acquired pneumonia in the ED. Am. J. Emerg. Med. 2018, 36, 347-351. [CrossRef]

34. Murad, A.; Li, P.Z.; Dial, S.; Shahin, J. The role of noninvasive positive pressure ventilation in community-acquired pneumonia. J. Crit. Care 2015, 30, 49-54. [CrossRef]

35. Valley, T.S.; Walkey, A.J.; Lindenauer, P.K.; Wiener, R.S.; Cooke, C.R. Association Between Noninvasive Ventilation and Mortality Among Older Patients with Pneumonia. Crit. Care Med. 2017, 45, e246-e254. [CrossRef] 
36. Stefan, M.S.; Priya, A.; Pekow, P.S.; Lagu, T.; Steingrub, J.S.; Hill, N.S.; Nathanson, B.H.; Lindenauer, P.K. The comparative effectiveness of noninvasive and invasive ventilation in patients with pneumonia. J. Crit. Care 2018, 43, 190-196. [CrossRef]

37. Johnson, C.S.; Frei, C.R.; Metersky, M.L.; Anzueto, A.R.; Mortensen, E.M. Non-invasive mechanical ventilation and mortality in elderly immunocompromised patients hospitalized with pneumonia: A retrospective cohort study. BMC Pulm. Med. 2014, 14, 7. [CrossRef]

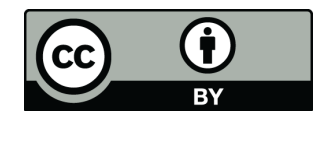

(C) 2020 by the authors. Licensee MDPI, Basel, Switzerland. This article is an open access article distributed under the terms and conditions of the Creative Commons Attribution (CC BY) license (http://creativecommons.org/licenses/by/4.0/). 